\title{
THE PROFITABILITY OF MOMENTUM TRADING STRATEGIES IN THE IRISH EQUITY MARKET
}

\author{
Fionnghuala $\mathrm{O}^{\prime}$ Sullivan and Niall O'Sullivan \\ Department of Economics and Centre for Investment Research, University College Cork
}

\begin{abstract}
W e examine the profitability of momentum-based trading strategies in the Irish equity market between 1988 and 2007. We investigate a range of trading strategies over alternative backward-looking ranking periods and forward-looking holding horizons as well as for alternative size momentum portfolios. We find that returns to momentum-based strategies are highly nonnormally distributed, giving rise to concern about the validity of inferences based on standard statistical tests of their abnormal performance. We therefore apply a bootstrap procedure to construct nonparametric $p$-values for the portfolio performance measures. Overall, we find little evidence that momentum-based trading strategies would have yielded an abnormal risk-adjusted return over the period. The Irish equity market appears to be quite efficient in this respect.
\end{abstract}

\section{INTRODUCTION}

Momentum-based investment strategies involve holding a portfolio of assets where each period the portfolio holdings are decided by a simple rule of buying past 'winner' assets and selling past 'loser' assets (from among the universe of assets available for selection). The strategy attempts to capture a momentum effect in the price movements of the underlying assets over consecutive time periods. Momentumbased trading strategies are of obvious interest to investors as they may provide an abnormal return at relatively low cost. First, the strategy can be constructed to be low cost where short positions fund long positions. Second, it is simple to implement as it does not require extensive research into asset selection. ${ }^{1}$

The existence of profitable momentum strategies among, for example, equity mutual funds, is well documented for the United States (US) (Jegadeesh and Titman, 1993, 2001), while Fletcher and Forbes (2002) report evidence that a 
substantial proportion of United Kingdom (UK) mutual funds also attempt to capture a momentum effect. In general, however, momentum effects are an underexplored phenomenon outside of the US equity market. In this study we examine the profitability of equity-based momentum strategies in the Irish market. The Irish market is an interesting case because of its comparatively low liquidity, low trading volume and high concentration of stock ownership, which may permit momentum effects to persist, at least in the short term. Studies of momentum investment strategies are also of general interest to researchers because findings of abnormal returns would be typically in breach of the efficient market hypothesis. However, it should be noted that, in fund performance literature, momentum risk factors are now widely specified in regression models (where the intercept is a measure of stock selection skill) in order to control for performance attributable to momentum effects which do not require 'skill', per se, on the part of the fund manager to capture (see Carhart, 1997).

We examine the profitability of momentum trading strategies in the Irish equity market by simulating and evaluating several different momentum portfolios based on alternative size portfolios, ranking periods (used to select equities) and holding periods. We examine the period February 1988 to December 2006. A recent paper by O'Donnell and Baur (2009) also examines momentum trading strategies in the Irish case. Over a similar sample period, the paper fails to find evidence of profitable strategies, although some abnormal returns are found during certain sub-periods. We extend the O'Donnell and Baur (2009) analysis by examining alternative size momentum portfolios and also by specifically investigating the effects of nonnormality in the momentum portfolio returns.

The study proceeds as follows: the next section briefly outlines some of the key findings from previous related studies and the following section describes the data and methodology used in this study. Then we describe our empirical findings, while the final section concludes.

\section{REVIEW OF THE LITERATURE}

Momentum trading has been widely examined in the literature for a number of alternative markets with variations across studies in terms of, inter alia, the length of historical horizons used to select stocks, holding periods lengths, sample periods and portfolio sizes. For example, Rouwenhorst (1998) found that momentum effects exist in European markets, Moskowitz and Grinblatt (1999) found momentum effects across industry-sorted portfolios, and Grundy and Martin (2001) found that momentum strategies have been consistently profitable in the US since the 1920s. There was some focus on relative strength strategies (that buy past winners and sell past losers) in early literature, most notably Levy (1967). However, as Levy arrived at this trading rule after investigating 68 different trading rules, it was believed that his result could be attributed to selection bias (Jegadeesh and Titman, 1993, p. 66).

Jegadeesh and Titman (1993) is a seminal paper in the area of momentum strategies. Using data from 1965 to 1989, the methodology involves selecting stocks based on their returns over the past one, two, three or four quarters and holding stocks 
for periods varying from one to four quarters. Specifically, securities are ranked in ascending order at the beginning of each period. Based on these rankings, ten equally weighted decile portfolios are formed. In each period, the strategy buys the top 'winner' portfolio and sells the bottom 'loser' portfolio, holding this position for $h$ periods. The authors show that stock returns exhibit momentum behaviour at intermediate horizons. They find that a strategy that uses a six-month historical ranking period can earn profits of about 1 per cent per month for the following year, after which the returns begin to dissipate. Their results indicate that these profits can be attributed to delayed stock price reactions to firm-specific information, not common factors. That the strategy is profitable in the medium term but unprofitable in the longer term is seen as evidence that the theories of investors either overreacting (in the case of contrarian strategies) or underreacting (in the case of relative strength strategies) to information are too simplistic. Instead, the authors deduce that investors who buy past winners and sell past losers move market prices from their long-term value temporarily, with a reversal after about a year. An alternative deduction is that the market underreacts to information about the short-term prospects of firms, which tend to be more ambiguous.

The results of Jegadeesh and Titman (1993) prompted a variety of interpretations, ranging from explanations of market inefficiency to compensation for risk and data mining. Conrad and Kaul (1998) argue that the apparent momentum arises because of cross-sectional variation in expected returns in adjacent time periods and is simply a compensation for risk. In direct contrast, others such as Daniel, Hirshleifer and Subrahmanyam (1998), Barberis, Shleifer and Vishny (1998) and Hong and Stein (1999) present behavioural models (see Barberis and Thaler (2003) for an expanded survey), which argue that the momentum effect arises because of a delayed overreaction to information that pushes the prices of winners (losers) above (below) their long-term values and, in subsequent periods, the returns of losers should exceed those of winners as prices re-adjust to the overreaction. Hence, such models predict that, in the 'post-holding' period, returns to a momentum strategy should be negative.

Jegadeesh and Titman (2001) evaluate the various explanations for the profitability of momentum trading strategies identified in the literature following their 1993 study. The authors offer evidence to refute the criticism that the momentum anomaly is a product of data mining by demonstrating that profitable momentum strategies persisted in the 1990s, after initially being identified in their earlier study of the 1980s. Jegadeesh and Titman (2001) do indeed find evidence that the performance of a momentum portfolio in the post-holding period (13 to 60 months) is negative, as predicted by Daniel et al. (1998) and others above.

While the bulk of the extant momentum literature relates to the US market, Rouwenhorst (1998) provides a comprehensive study of the European market, using data from twelve countries: Austria, Belgium, Denmark, France, Germany, Italy, the Netherlands, Norway, Spain, Sweden, Switzerland and the United Kingdom. Employing a similar procedure to that of Jegadeesh and Titman (1993), the paper finds the strategy to be as profitable using European stock prices as it is using US stock prices, yielding approximately 1.16 per cent per month for the following year, with reversal thereafter. However, Rouwenhorst (1998) notes that an international 
momentum strategy may not be well diversified. A dominant performance by one country will subsequently cause the winner portfolio to overweight that country. In examining this further, the paper constructs momentum portfolios that weight stocks by ranking them based on past performance relative only to stocks listed in the same country. However, momentum portfolio returns using this revised strategy remain highly profitable at 0.93 per cent per month, suggesting that individual country momentum does not explain the success of the European-wide strategy. However, the Rouwenhorst (1998) results do show a variation in excess returns ('winner' portfolio minus 'loser' portfolio) across European countries. Although momentum effects are present in all countries, the strongest profits were experienced by Spain, followed by the Netherlands, Belgium and Denmark. Sweden is the only country that doesn't experience significant profits in this period, with portfolios earning 0.16 per cent excess returns per month.

Moskowitz and Grinblatt (1999) question whether the apparent profitability of momentum strategies arises because of industry effects. They formulate a momentum strategy based on returns of different industries and test it using stock prices from 1963 to 1985 on the NYSE (New York Stock Exchange), AMEX (American Stock Exchange) and NASDAQ (originally the National Association of Securities Dealers Automated Quotations Systems) indices. They also test the individual stock price momentum strategy used by Jegadeesh and Titman (1993) in order to compare the two strategies. They report that momentum returns exist in industry-based portfolios, which are more profitable than individual stock price momentum strategies, claiming that much of the profit derived from the latter is eroded after controlling for industry effects. Of course, the further implication here is that momentum portfolios are not well diversified, as winners and losers are from the same industry; hence momentum returns may be a compensation for risk and not a market inefficiency.

Jegadeesh and Titman (1993) also investigated the hypothesis that stock prices overreact to information in an extension of the contrarian strategies developed by DeBondt and Thaler (1985, 1987). Contrarian strategies involve buying (selling) stocks that have been performing poorly (well) in recent months. DeBondt and Thaler (1985) explore the consequences of people's tendencies to overreact to information such as unexpected or dramatic news events. They find that people tend to emphasise recent information too much and underweight previous information. As a result of investor overreaction, they believe it is possible that stock prices might temporarily depart from their fundamental values. If this is the case, buying past losers would be a more profitable strategy than buying past winners. Their results show that forming portfolios of past 'losers' reaped exceptionally large January returns as far as five years on. Their conclusion is that stocks that experienced extreme long-term gains or losses tended to undergo systematic price reversals. DeBondt and Thaler (1987) form portfolios of the most extreme losers and winners as measured by excess cumulative returns over successive five-year formation periods. Their results show that the loser portfolio outperforms the winner portfolio by an average of 31.9 per cent over the following five-year test period. In order to reconcile the findings that both contrarian strategies and momentum strategies are profitable, even though they consist of taking opposite actions, Jegadeesh and 
Titman (1993) consider different time horizons. Contrarian strategies are found to be profitable using returns over the very long term (three to five years) or over the very short term (one week to one month). Relative strength strategies base their selection on price movements over the medium horizon (three to twelve months).

The Irish case has been examined recently by O'Donnell and Baur (2009). Over the period 1984-2007 the authors examine momentum portfolios (winner minus loser) as well as winner and loser portfolios separately. Over the full sample period, the authors find no evidence of profitable momentum strategies, although some evidence is found examining alternative sub-periods of high, low and negative market growth. First, however, O'Donnell and Baur (2009) form momentum portfolios comprising the top and bottom third of stocks. In our paper, we look further into alternative size portfolios to identify possible profitable momentum strategies among the more extreme winner and loser stocks. Second, O'Donnell and Baur (2009) report standard statistical tests of risk-adjusted return. However, we find that portfolios of winner and loser stocks are both highly non-normally distributed and serially correlated - so much so that questions arise as to the validity of the standard statistical tests such as t-tests. To examine the robustness of the $\mathrm{O}^{\prime}$ Donnell and Baur (2009) conclusions, we apply a bootstrap procedure in our paper and derive nonparametric $p$-values in our statistical tests.

As past findings have been found to be sensitive to using different ranking and holding period lengths, the analysis in this paper is conducted testing alternative time horizons in this regard, as well as alternative size momentum portfolios, in order to capture these dynamics and examine the robustness of results.

In a related area of the literature, the question of momentum effects also arises in fund performance evaluation. As this is somewhat tangential to the focus of this study, we do not propose to discuss it in detail here. Instead, we briefly refer the interested reader to some important contributions to the area. Carhart (1997) demonstrates, inter alia, that momentum effects explain around half of the crosssectional spread between the top and bottom decile portfolios of mutual funds ranked by performance. Chen, Jegadeesh and Wermers (2000) examine the past returns of the current constituent stock holdings of winning and losing funds, and find that stocks currently held by winning funds have higher past returns, or momentum, than stocks held by losing funds. The raw returns of the winning funds go on to outperform the returns of losing funds for the subsequent two quarters. The risk-adjusted returns of winning funds go on to outperform those of losing funds, for the subsequent quarter. Grinblatt and Titman (1992) and Hendricks, Patel and Zeckhauser (1993) report some evidence that the source of the fund performance persistence found in their studies lies in a momentum effect in the fund's stock holdings rather than in persistent stock-picking ability on the part of the fund manager.

A summary of the main findings from the momentum strategy literature is presented in Table 1 . There is some variability in these findings due to variations in country/index, historical horizons, holding periods and the type of strategy examined, as indicated. All studies find momentum strategies to be profitable to some degree. The majority of the investigations have been carried out on US data, with little research on European indices. 
O'Sullivan and O'Sullivan

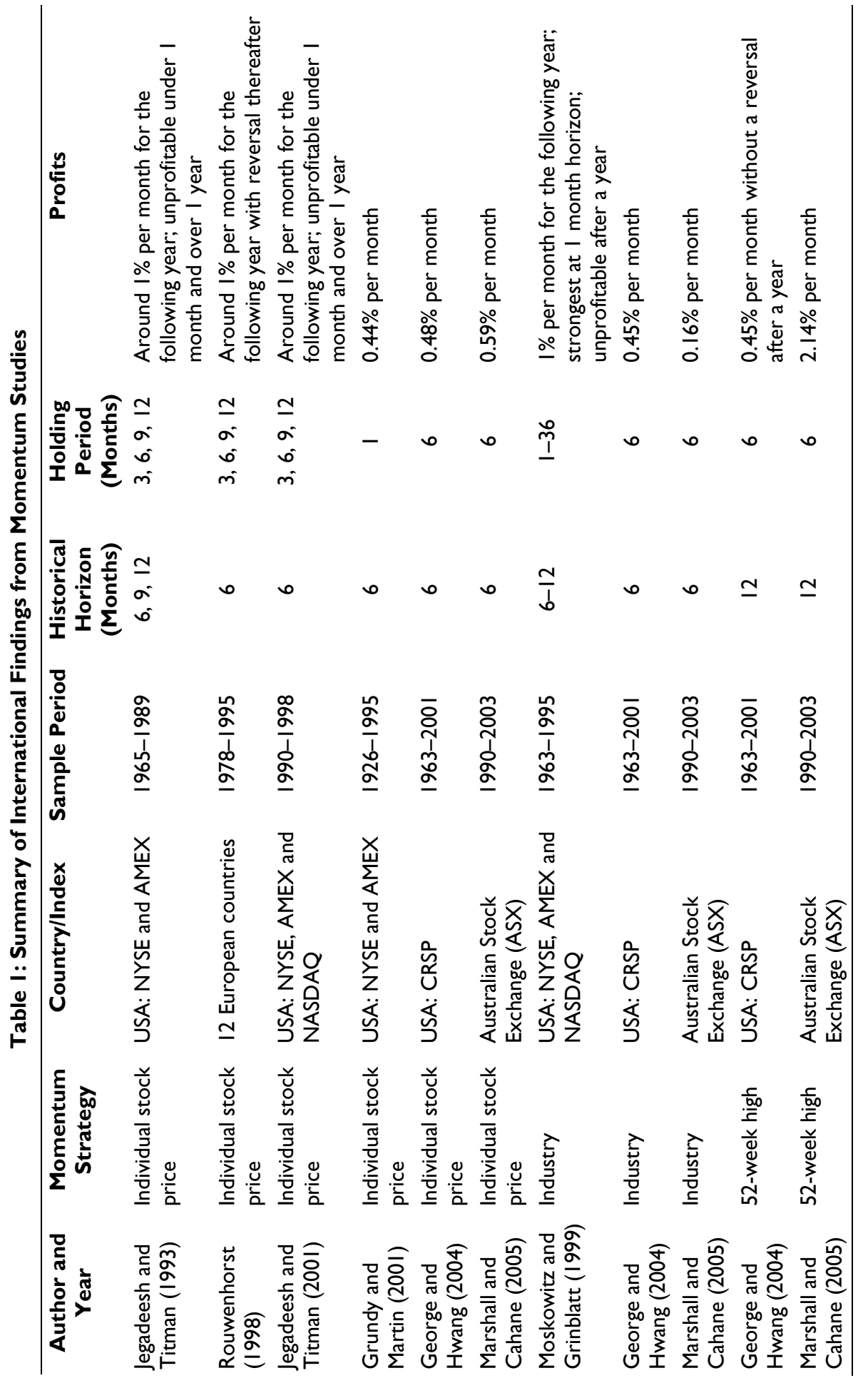

60 


\section{DATA AND METHODOLOGY}

To construct momentum portfolios, at month $t$ we rank all stocks in ascending order of raw return based on a past period of $r$ months. Based on these rankings, two equally weighted portfolios, each of size $s$, are formed. The winner (loser) portfolio comprises the top (bottom) performing stocks. The strategy involves buying (selling) the winner (loser) portfolio and holding for $h$ months. The momentum portfolio return between time $t$ and $t+1$ is the return on the winning portfolio minus the return on the losing portfolio over this holding period. This is then carried out recursively each month to generate a time series of returns. In this study, we examine momentum portfolios for alternative values of $r=3,6,11 ; h=1,3,6$; and $s=$ top/ bottom 30 per cent of stocks, top/bottom 10 per cent of stocks and top/bottom 5 stocks. We then test for abnormal performance in the momentum portfolio by estimating the risk-adjusted return $-\alpha_{i}-$ in the least squares regression of the Capital Asset Pricing Model (CAPM), as follows:

$R_{i t}-R_{f t}=\alpha_{i}+\beta_{i}\left(R_{m t}-R_{f t}\right)+\varepsilon_{i t}$

where $R_{i t}$ is the return on portfolio $i, R_{m t}$ is the return on a market factor-mimicking portfolio and $R_{f t}$ is a risk-free rate. A statistically significant positive value of alpha is taken to indicate superior performance in the momentum trading strategy. Here, $R_{m t}$ is the returns on the Irish Stock Exchange Quotient (ISEQ) index, while $R_{f t}$ is proxied by the one-month interbank rate. Our entire analysis is conducted on monthly returns.

Our data set, which covers the period February 1988 to December 2006, includes all stocks listed on the ISEQ index. This also includes all de-listed and dead stocks over the period. Therefore, portfolios of past winners and losers are calculated at each time $t$, based on the full set of stocks that were available to fund managers at that time historically and not just based on the historical time series of stocks that exist at the end of the sample period. This avoids the possible problem of survivorship bias. If a stock drops out of the database during a holding period, the portfolio is rebalanced to be equally weighted across all the remaining stocks.

Our investigation of momentum trading profitability extends that of $\mathrm{O}^{\prime}$ Donnell and Baur (2009) in two key respects. First, we find that all the momentum portfolios demonstrate returns that are highly non-normally distributed, potentially invalidating the inferences from standard statistical tests such as t-tests in Equation 1. This should not be too surprising as momentum portfolios comprise stocks in the tails of the cross-section distribution, where non-normality is typically greatest (see Cuthbertson, Nitzsche and O'Sullivan, 2008). Therefore, we apply a bootstrap procedure to generate nonparametric $\mathrm{p}$-values for the performance estimates of each of the momentum portfolios. To do this, the performance measurement model is first estimated by Ordinary Least Squares (OLS). The estimated coefficients and OLS residuals $\hat{\alpha}_{i}{ }^{\prime} \hat{\beta}_{i}$ and $\hat{\varepsilon}_{i t}$ are saved. In the next step, a random sample of residuals of size $\mathrm{Ti}$ is drawn (with replacement) from $\hat{\varepsilon}_{i t}$. Using the estimated factor loadings from step one and the original chronological ordering of $R_{m t}$ and setting $\hat{\alpha}_{i}=0$ under the null hypothesis of no abnormal performance, bootstrap simulated returns, $\tilde{R}_{i t}$, 
are constructed. By construction, this bootstrapped or simulated portfolio return has a 'true' abnormal performance of zero. Using these bootstrap fitted returns, the performance measurement model is re-estimated and a bootstrap estimate of abnormal performance under the imposed null hypothesis is obtained, denoted $\tilde{\alpha}_{i}$. This $\tilde{\alpha}_{i}$ represents random sampling variation around a true value of zero. This simulation process is repeated $\mathrm{B}=1,000$ times. The 1,000 values of $\tilde{\alpha}_{i}$ represent the nonparametric distribution of $\hat{\alpha}_{i}$ under the null hypothesis. We can then examine where the OLS estimate of $\hat{\alpha}_{i}$ lies relative to the distribution of $\tilde{\alpha}_{i}$ to determine a nonparametric p-value for $\hat{\alpha}_{i}$, which makes no prior assumptions regarding the normality of returns. So, for example, a p-value $=0.10$ indicates that only 10 per cent of the values of $\tilde{\alpha}_{i}$ are greater than $\hat{\alpha}_{i}$, suggesting that there is only a 10 per cent chance of observing the estimated value of $\hat{\alpha}_{i}$ where the 'true' value of $\alpha_{i}$ is zero. We can also use the t-statistic of alpha as a measure of abnormal performance. The t-statistic has the advantage that it controls for the standard error and may therefore give a more reliable estimate of abnormal performance relative to $\hat{\alpha}_{i}$. The same bootstrap procedure as above can be used to generate $t_{\tilde{\alpha}_{i}}$ and hence the nonparametric distribution of the t-statistic of $\hat{\alpha}_{i}$ - denoted $t_{\hat{\alpha}_{i}}$ - under the null hypothesis. In this study we report the nonparametric p-values of $t_{\hat{\alpha}_{i}}$. Furthermore, in the calculation of all t-statistics in this study, we use Newey-West serial correlation and heteroscedasticity adjusted standard errors. Adopting such a bootstrap procedure to account for non-normal stock returns is not typically done in the extant momentum literature. Second, the O'Donnell and Baur (2009) study investigates momentum portfolios comprising the top and bottom third of stocks. One concern is that such large portfolios may disguise profitable momentum-based strategies among more extreme winner and loser stocks, e.g. top and bottom 10 per cent of stocks or, say, top and bottom five stocks. One advantage of these latter cases is that the pursuit of the momentum strategy may involve lower transactions costs on the part of the fund in rebalancing the fund holdings each period. In this study, we also report findings for momentum trading strategies based on the top and bottom 10 per cent and the top and bottom five stocks.

\section{EMPIRICAL RESULTS}

Our main findings are presented in Table 2, which shows results for the full sample period February 1988 to December 2006. Performance estimates are reported for momentum-based portfolios for alternative ranking and holding periods as indicated in each column. For example, the column headed ' $3-1$ ' refers to a past ranking period of three months and a holding period of one month. Results are also reported for alternative size momentum portfolios, including the top 30 per cent minus the bottom 30 per cent, the top 10 per cent minus the bottom 10 per cent and the top five minus the bottom five stocks, as indicated. 'Alpha' is the riskadjusted monthly percentage return from the OLS estimation of Equation 1 while 't-alpha' is the corresponding t-statistic (Newey-West adjusted for serial correlation and heteroscedasticity). 
The Profitability of Momentum Trading Strategies in the Irish Equity Market

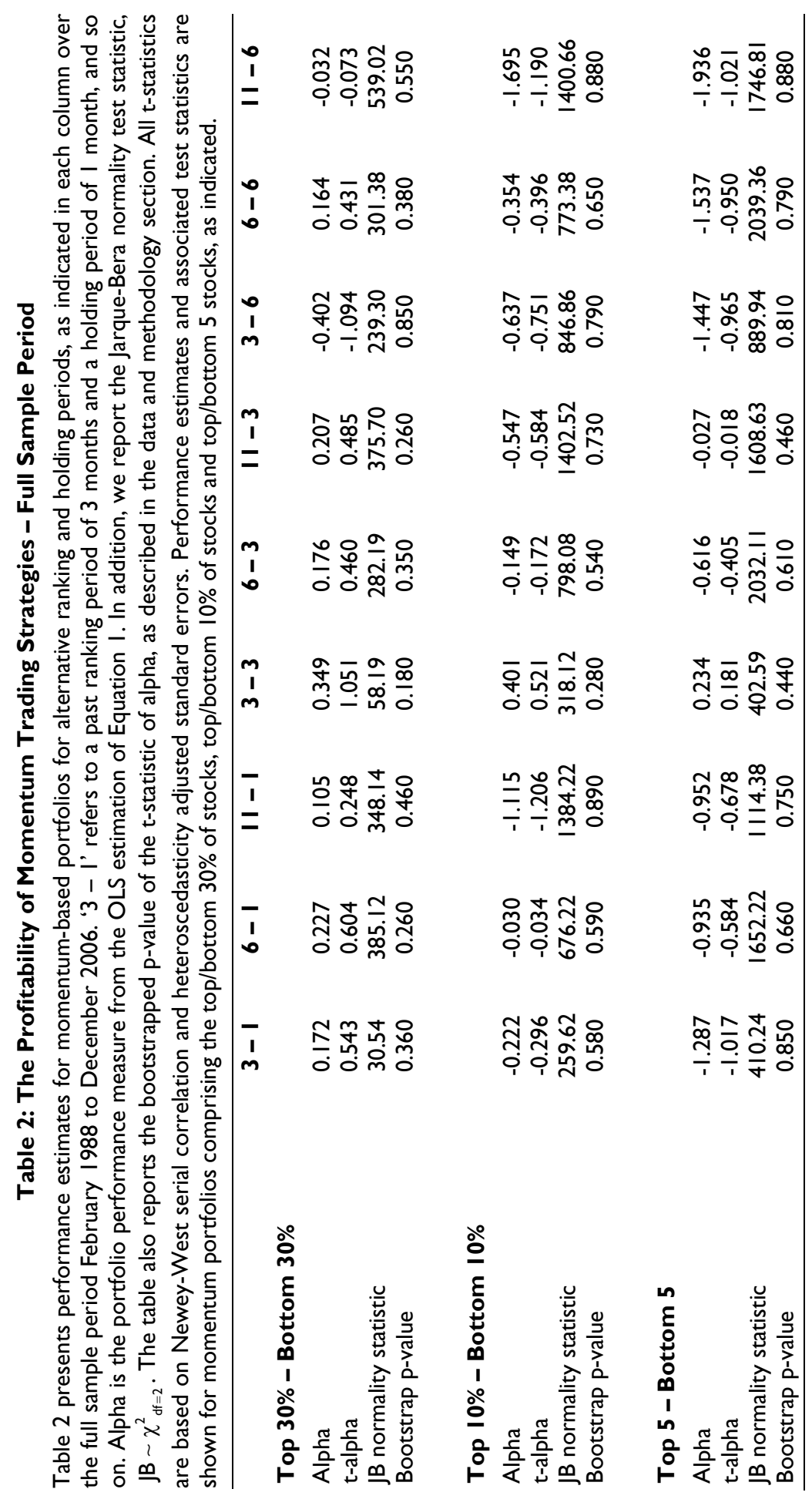


From the t-statistics it is clear that none of the momentum portfolios yielded statistically significant positive returns (at the 5 per cent significance level) over the full period, and, indeed, in several cases, returns are negative. Table 2 also shows results of tests of the normality of the regression residuals. Here, we report the Jarque-Bera test statistic, JB $\sim \chi_{\mathrm{df}=2}^{2}$. The $\chi^{2}$ critical value at 5 per cent significance is 5.99. It is immediately evident that, in the case of all portfolios, the null hypothesis of normally distributed residuals is strongly rejected. In turn, this suggests that the alpha estimates are also non-normally distributed, thus potentially questioning the reliability of findings based on t-tests. This motivates our use of the bootstrap procedure to generate nonparametric $\mathrm{p}$-values in order to investigate the robustness of momentum findings. In Table 2, these p-values are denoted as 'Bootstrap p-value'. The p-values, all greater than 0.05 , indicate that none of the momentum portfolios yield positive and statistically significant returns at 5 per cent significance (or even at the 10 per cent significance level).

The full set of results in Table 2 lead us to conclude that, over the full sample period, momentum trading strategies did not yield a positive risk-adjusted return in the Irish equity market. This finding is remarkably robust to alternative ranking windows and holding periods as well as to alternative size momentum portfolios. It also proves robust to alternative statistical testing methodologies, which account for the finding of non-normally distributed returns data. These overall findings are qualitatively similar to those of O'Donnell and Baur (2009).

However, O'Donnell and Baur (2009) go on to explore the profitability of momentum portfolios separately during periods of low versus high growth in the stock market and report evidence of abnormal returns in the latter, but not the former. It is in this analysis that we find that results are somewhat sensitive to (i) the non-normality issue, (ii) the size of momentum portfolios and (iii) the ranking and holding windows. Table 3 presents findings for the later relatively high stock market growth period of September 1995 to December 2006 (dates chosen for consistency of comparison with O'Donnell and Baur (2009)). ${ }^{2}$ The upper panel of Table 3 shows results for the largest momentum portfolios of the top 30 per cent minus the bottom 30 per cent of ranked stocks. Here, according to the standard t-statistics, two of the momentum portfolios yield a positive and significant abnormal return at the 10 per cent significance level, i.e. the portfolios of ' $11-3$ ' and ' $11-6$ ' ranking and holding periods. However, examining the nonparametric p-values of the t-statistics from the bootstrap procedure, we find that four of the portfolios are profitable at 10 per cent significance. That is, the parametric t-tests and the more robustly estimated nonparametric $p$-values from the bootstrap procedure give conflicting inferences regarding the profitability of some the momentum trading strategies, highlighting the potential for non-normality in financial data to invalidate the findings of many standard statistical tests.

From Table 3, we find that one of the smaller momentum portfolios (top 10 per cent minus bottom 10 per cent) with a 3 - 6 ranking/holding period yields a positive and significant abnormal return at 10 per cent significance. However, all other portfolios, regardless of size or holding and ranking periods, yield insignificant (and sometimes negative) returns by both the standard t-tests and the nonparametric p-values. 
The Profitability of Momentum Trading Strategies in the Irish Equity Market

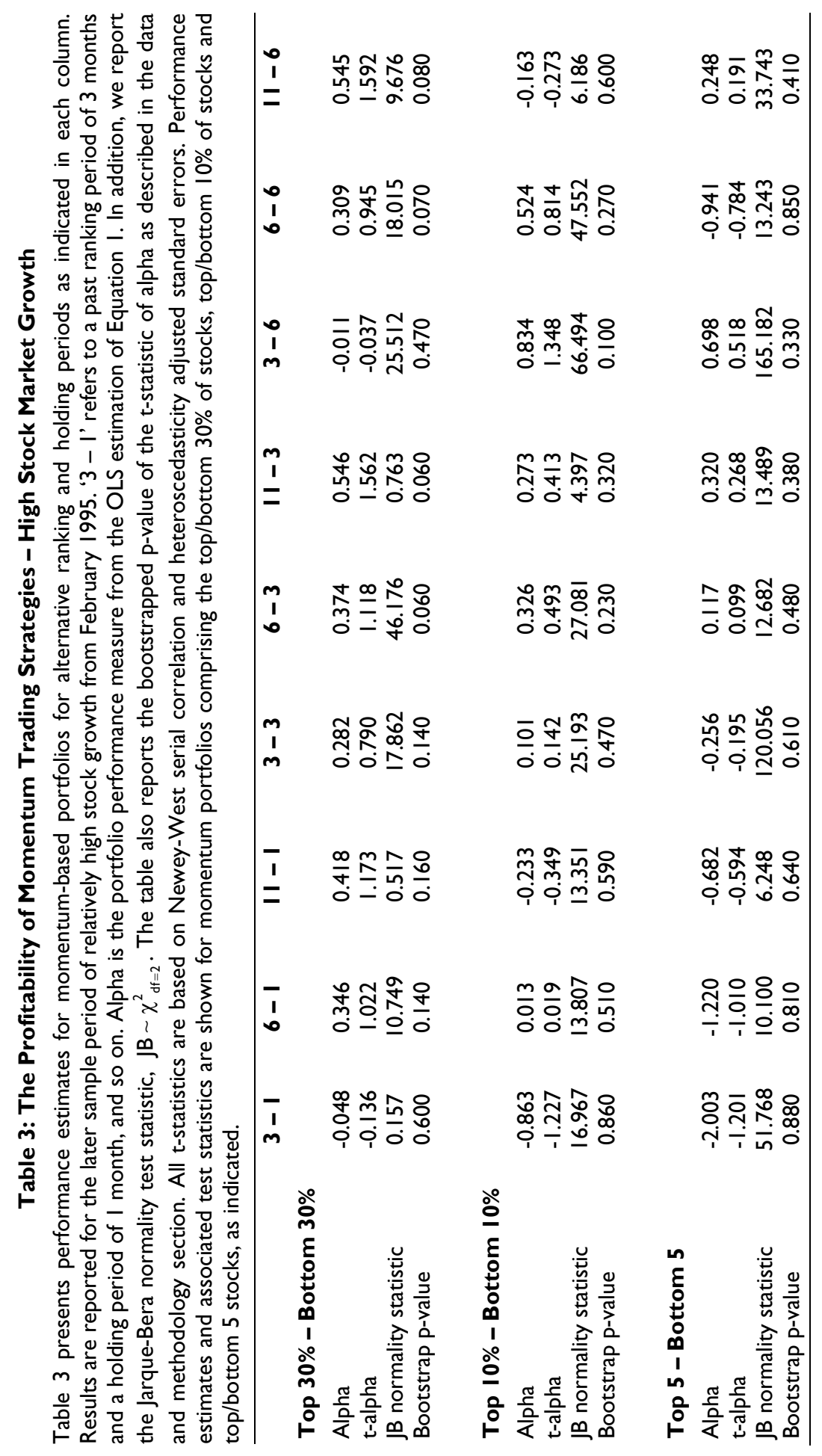


There are some further surprises in the results. First, the finding that profitable momentum strategies are more prevalent among larger rather than smaller portfolios suggests that the momentum effect is not driven by the extreme winner and loser stocks but instead is driven by those slightly further inside the tail of the crosssection distribution of stock returns. Alternatively, there may be more volatility among the more extreme winner and loser stock returns, leading to less persistence, even in the short term. Second, momentum is stronger among portfolios of longer ranking and holding windows. That a longer ranking period provides a more reliable ranking of stocks in the momentum strategy is intuitive, but one might have expected that, in an efficient market, the momentum effect in stocks would dissipate quickly and hence would be better captured by shorter rather than longer holding periods.

Overall, the findings in Table 2 strongly suggest that momentum-based trading strategies in the Irish equity market failed to yield abnormal returns over the longer sample period under investigation. Results presented in Table 3 do show some evidence of momentum trading profitability but highlight the sensitivity of results to non-normality, momentum portfolio sizes, and ranking and holding period lengths. Furthermore, these abnormal returns are found only in conditions of relatively high market growth. ${ }^{3}$ As these conditions are comparatively rare and their persistence unreliable, our overall analysis finds against the existence of abnormal returns from momentum-based equity trading in the Irish market. Given this principal finding at the level of gross returns, we do not further explore issues of (i) transactions costs and (ii) market depth and liquidity, i.e. if the stocks which must be traded are only available in small volumes then pursuit of the strategy may affect prices in a manner that would kill off the phenomenon being observed. These issues may eliminate momentum-based returns, if they had been found to exist. In our reading we find these issues are underinvestigated in the momentum literature.

\section{CONCLUSION}

This study examines the profitability of momentum-based trading strategies in the Irish equity market between 1988 and 2007. Investigating a range of trading strategies over alternative backward-looking ranking periods and forward-looking holding horizons as well as for alternative size momentum portfolios, we find that returns to momentum-based strategies are highly non-normally distributed, giving rise to concern about the validity of inferences based on standard statistical tests. We apply a bootstrap procedure to construct nonparametric p-values for the momentum portfolio performance measures. Overall, we find little evidence that momentum-based trading strategies would have yielded an abnormal riskadjusted return over the period. Our overall results are qualitatively similar to those of O'Donnell and Baur (2009) but contribute to this literature by highlighting that (i) the non-normality of stock returns, particularly in the tails of the cross-section distribution, must be considered if robust inferences are to be drawn from this type of study, and (ii) the most extreme winner and loser stock returns appear to detract from rather than drive profitable momentum portfolios, where these exist at all. 
It is interesting, perhaps even counterintuitive, that momentum trading does not prove profitable in a smaller, less liquid market, while there is evidence of profitable momentum strategies in larger markets such as the US. It may be that larger, higher volume markets involve relatively high positive feedback (noise) trading compared to smaller markets, which makes the momentum strategy partly self-fulfilling in the short term. We leave this question for future research.

\section{ACKNOWLEDGEMENTS}

We are grateful for financial support from the Irish Research Council for the Humanities and Social Sciences (IRCHSS). We also wish to thank anonymous referees for helpful comments and suggestions. Main programmes use Gauss.

\section{NOTES}

1. Of course, transaction costs incurred will be related to the degree of portfolio turnover, but clearly a portfolio manager has some discretion here.

2. We do not present results for the earlier lower growth period as, similar to Table 2, they consistently show no significant return to momentum trading across all portfolios.

3. In addition, these abnormal returns may disappear if the performance model was expanded from a CAPM single-factor model to the Fama and French three-factor model. However, we do not expand on this here as we don't wish to advance a theory, a priori, that the size and value effects would be systematically different in an up- versus down-market.

\section{REFERENCES}

Barberis, N. and Thaler, R. (2003). A Survey of Behavioural Finance, in G.M. Constantinidis, M. Harris and R. Stulz (eds.), Handbooks of the Economics and Finance, Elsevier Science B.V.

Barberis, N., Shleifer, A. and Vishny, R. (1998). A Model of Investor Sentiment, Journal of Financial Economics, Vol. 49, Fall, pp. 307-343.

Carhart, M. (1997). On Persistence in Mutual Fund Performance, Journal of Finance, Vol. 52, No. 1, pp. 57-82.

Chen, L., Jegadeesh, N. and Wermers, R. (2000). The Value of Active Mutual Fund Management: An Examination of the Stock Holdings and Trades of Fund Managers, Journal of Financial and Quantitative Analysis, Vol. 35, No. 3, pp. 343-368.

Conrad, J. and Kaul, G. (1998). An Anatomy of Trading Strategies, Review of Financial Studies, Vol. 11, No. 3, pp. 489-519.

Cuthbertson, K., Nitzsche, D. and O'Sullivan, N. (2008). UK Mutual Fund Performance: Skill or Luck?, Journal of Empirical Finance, Vol. 15, No. 4, pp. 613-634.

Daniel, K., Hirshleifer, D. and Subrahmanyam, A. (1998). Investor Psychology and Security Market Under- and Overreactions, Journal of Finance, Vol. 53, No. 6, pp. 1839-1886.

DeBondt, W.F.M. and Thaler, R. (1985). Does the Stock Market Overreact?, Journal of Finance, Vol. 40, No. 3, pp. 793-805.

DeBondt, W.F.M. and Thaler, R. (1987). Further Evidence of Investor Overreaction and Stock Market Seasonality, Journal of Finance, Vol. 42, No. 3, pp. 557-581. 
O'Sullivan and O'Sullivan

Fletcher, J. and Forbes, D. (2002). An Exploration of the Persistence of UK Unit Trust Performance, Journal of Empirical Finance, Vol. 9, No. 5, pp. 475-493.

George, T.J. and Hwang, C.Y. (2004). The 52-Week High and Momentum Investing, Journal of Finance, Vol. 59, No. 5, pp. 2145-2176.

Grinblatt, M. and Titman, S. (1992). The Persistence of Mutual Fund Performance, Journal of Finance, Vol. 47, No. 5, pp. 1977-1984.

Grundy, B.D. and Martin, J.S. (2001). Understanding the Nature of the Risks and the Source of the Rewards to Momentum Investing, Review of Financial Studies, Vol. 14, No. 1, pp. 29-78.

Hendricks, D., Patel, J. and Zeckhauser, R. (1993). Hot Hands in Mutual Funds: Short-Run Persistence of Performance, 1974-1988, Journal of Finance, Vol. 48, No. 1, pp. 93-130.

Hong, H. and Stein, J. (1999). A Unified Theory of Underreaction, Momentum Trading and Overreaction in Asset Markets, Journal of Finance, Vol. 54, No. 6, pp. 2143-2184.

Jegadeesh, N. and Titman, S. (1993). Returns to Buying Winners and Selling Losers: Implications for Stock Market Efficiency, Journal of Finance, Vol. 48, No. 1, pp. 65-91.

Jegadeesh, N. and Titman, S. (2001). Profitability of Momentum Strategies: An Evaluation of Alternative Explanations, Journal of Finance, Vol. 56, No. 2, pp. 699-720.

Levy, R. (1967). Relative Strength as a Criterion for Investment Selection, Journal of Finance, Vol. 22, No. 4, pp. 595-610.

Marshall, B.R. and Cahane, R.M. (2005). Is the 52-Week High Momentum Strategy Profitable Outside the US? Applied Financial Economics, Vol. 15, No. 18, pp. 1259-1267.

Moskowitz, T.J. and Grinblatt, M. (1999). Do Industries Explain Momentum?, Journal of Finance, Vol. 54, No. 4, pp. 1249-1290.

O'Donnell, D. and Baur, D. (2009). Momentum in the Irish Stock Market, Applied Economics Letters, Vol. 16, No. 11, pp. 1133-1138.

Rouwenhorst, K.G. (1998). International Momentum Strategies, Journal of Finance, Vol. 53, No. 1, pp. 267-284. 